\title{
Implication of METT framework for assessing the performance of ecosystems and biodiversity in three protected areas of Balochistan being managed with different mechanism
}

\author{
Faiz Mohammad Kakar ${ }^{*}$, Syed Ainuddin ${ }^{2}$, Zahoor Ahmad Bazai ${ }^{3}$ and \\ Saeed Ur Rehman Kakar ${ }^{3}$ \\ 1. Pakistan Study Center, University of Balochistan, Quetta-Pakistan \\ 2. Department of Disasters Management and Development Studies, University of Baluchistan-Pakistan \\ 3. Botany Department, University of Balochistan, Quetta-Pakistan \\ *Corresponding author's email: faizkakar@yahoo.com
}

Citation

Faiz Mohammad Kakar, Syed Ainuddin, Zahoor Ahmad Bazai and Saeed Ur Rehman Kakar. Implication of METT framework for assessing the performance of ecosystems and biodiversity in three protected areas of Balochistan being managed with different mechanism. Pure and Applied Biology. Vol. 8, Issue 1, pp331-342. http://dx.doi.org/10.19045/bspab.2018.700155

\begin{tabular}{llll}
\hline \hline Received: 20/06/2018 & Revised: 10/09/2018 & Accepted: 11/09/2018 & Online First: 12/09/2018 \\
\hline \hline
\end{tabular}

\section{Abstract}

The Biodiversity conservation is facing great challenge in the era of climate change. The conservation of Biodiversity with different procedures is being exercised. The approaches used for effective management of Protected Areas (PAs) are not only accepted globally but also target increasing the size of PAs up to 17\% of terrestrial area till 2020. In this milieu Pakistan is striving hard to increase number and size of PAs. However, it is unanimously recognized as the management of Pas matters enormously for Biodiversity conservation and is concerned with quality assurance. The current study was aimed at using globally recommended Management Effectiveness Tracking Tool (METT) by World Wildlife Fund (WWF) and World Bank (WB) to comparatively analyze the management effectiveness of the three targeted PAs of Balochistan, namely Chiltan National Park, Torghar, and Ziarat Juniper Man and Biosphere (MAB) being managed by Government, local communities and jointly by both Government and local communities respectively. The results of study revealed that the overall management of our three selected PAs in Balochistan was found better than the average status of 331 PAs assessed by WWF threshold standards. Out of 30 indicators, 23 indicators scored high level whereas 6 indicators were found weak dependent on security situation and poor governance in the province. Torghar ranked on top followed by Chiltan National Park and Ziarat Juniper MAB that ranked second and third, respectively. In conclusion, our research will provide better guidelines for policy makers in the effective management of PAs. The study has presented a baseline data for further research and will serve the stakeholders for initiating further steps regarding PAs in Balochistan.

Keywords: Balochistan; Biodiversity; Conservation; Protected Areas (PAs)

Introduction

Protected areas (PAs) are the central part of any national biodiversity strategy and key components of environmental conservation, 
providing a number of invaluable advantages to humanity $[1,2]$. They are at the forefront of conservation efforts for having a number of ecosystems that maintain the crop diversity and species with economic value. Pas also have the capacity for water retention, erosion control, fuel wood, shelter, reduced flooding and unnatural wild fires. Most of the local and rural communities depend on the Pas for their food, health and livelihoods. In addition, local communities are also protected against adverse environmental risks of floods and droughts [3, 4]. PAs contribute directly to global sustainable development and poverty reduction $[2,5]$.

The ecosystems in PAs provide benefits of various natures at all levels [6]. It is estimated that nearly 1.1 billion people (one six th of the world's population) depend on PAs for a significant percentage of their livelihoods (UN Millennium Project 2005). It is often hard to quantify the advantages of ecosystems in an accurate manner and to considerate the relation between ecosystems and livelihood. It was estimated that the global value of biodiversity to be roughly $\$ 38$ trillion and the advantages of land conservation (and subsequent loss of ecosystem services) were always outweighed by the costs [1]. The management of ecosystem biodiversity in PAs is becoming very challenging in developing countries due to multiple factors such as increasing population, new ways of income, industries and development initiatives [7]. To assure the good governance for environmental protection at national level, Pakistan signed a number of international environmental conventions, treaties and laws regarding, climate change, biodiversity, endangered species, wetlands, desertification, hazardous wastes, environmental modification, ozone layer protection, sea law, marine dumping and ship pollution [8]. Pakistan paved the very first step in 1983 for political environmental governance by initiating environment protection ordinance and widely publicized a number of legislations regarding environmental governance. This Environment Protection Ordinance is a benchmark of quality for environmental legislation and a holistic approach to environmental issues [9].

In compliance with Pakistan's Biodiversity Action Plan, 2000, there is a network of 225 PAs in Pakistan encompassing 99 Wildlife Reserves, 14 National Parks, 96 Game Reserves, and 16 uncategorized regions. The total area is 9,170,121 ha, covering $10.4 \%$ total land area of Pakistan. Although there are 29 National Parks in Pakistan, however, only 14 are under the special consideration of International Union for Conservation of Nature (IUCN). These PAs are being managed either exclusively by government or co-managed by NGOs, local communities or private sect (Kothari, 1999). Pakistan is struggling to overcome the challenges being faced in managing the PAs. However, some of the issues involved are very complicated and require foreign support and assistance. One of the major challenges being faced is climate change. The uncontrolled extraction of resources from forest is not a factor responsible for the loss of biodiversity but the state government that grabs about $50 \%$ revenue from forest resources. Out of this revenue, $94 \%$ is generated from timber sale by Azad Jammu and Kashmir Logging and Sawmills Corporation (AKLASC) and 06\% by non-timber forest products (NTFP). Undoubtedly, the situation emphasizes for a long term planning and stresses on shifting the dependency on the other resources [10]. With such a critical scenario across the country, Balochistan, the largest but less developed province of Pakistan, is suffering the same situation. Thus both the political and social authorities have to take serious steps for controlling the challenges being faced in the management of conserved ecosystems and biodiversity in PAs. The 
management of PAs demand for possible and solid recommendations based on detailed, reliable and authentic research which is the objective of present study. The study is aimed to assess the management effectiveness with the application of WB designed and recommended Management Effectiveness Tracking Tool (METT) for comparative analysis of three selected PAs of Balochistan being managed with three different types of mechanisms: (1) by Public Institution, (2) by Public Institution and Local community and (3) by private by local community.

\section{Materials and methods}

The methodology for this study is descriptive. The study is undertaken to highlight the better mechanisms for management of PAs by assessing the management effectiveness of the three PAs with the aim to influence the policy makers to implement a scientifically tested and proved mechanism for management of PAs in future.

\section{Selection of protected areas}

Three PAs were selected and assessed in the province of Balochistan based on the following criteria:

1. The PAs must be recognized at the provincial, national and international level and registered in World Database of Protected Areas (WDPA).

2. The selected PAs must have different management mechanisms for comparative analysis:

a. PAs entirely managed by Government with no involvement of local community.

b. PAs co-managed by Government with local community involvement

c. PAs purely managed by local community Keeping in Consideration the above criteria, the three selected National PAs for our study in the province of Balochistan were (1) Chiltan National Park, (2) Ziarat Juniper MAB and (3) Torghar. The registration numbers of targeted PAs was searched in WDPA which are internationally registered with WDPA https://protectedplanet.net/country/PK\#ref1 and being managed by Government, Government and local community and local community (Figure 1).

METT questionnaire and its categories

METT with a guided questionnaire was used in present study for comparative analysis to assess and measure the management effectiveness of three targeted PAs in Balochistan. METT is standardized and globally applicable tool for all types of PAs. It is widely used by WWF/WB to evaluate the progress for improving management effectiveness of PAs. METT has some key characteristics such as harmonized record system, appropriate for reproduction, generating reliable data to allow progress tracking over time, relatively quick and easy to be filled by PA staff and score analysis. METT consist of 30 questions categorized in five sections such as (1) Context, (2) Inputs, (3) Planning, (4) Process and (5) Outputs/Outcomes. There are four scores categories ( 0 to 3 ) indicating the levels of management effectiveness at PAs where score " 0 " depicts poor management, score " 1 " depicts fair management, score " 2 " depicts good management and score " 3 " depicts excellent management.

\section{Data collected}

Data was collected as per the guidelines of WB booklet for METT utilization. METT questionnaires were filled out by interviewing the PA staff. PA staff comprised of District Forest Officers, Ranger Officers, Forest Officers, Conservators, Helpers and Security Guards. In community managed PAs, questionnaire were filled out by approaching office bearers, conservators, community members and tribal leaders involved in PA protection.

\section{Standard comparative analysis of study}

A well-known study [11] entitled "Tracking Progress in Managing PAs around the World" conducted by WWF and WB across 
the world in 55 countries investigating METT applications developed by WB and WWF in the management effectiveness of 331 PAs has been considered a baseline for comparative analysis of targeted PAs in our study. The Average data of all 30 indicators of METT has been considered as threshold.

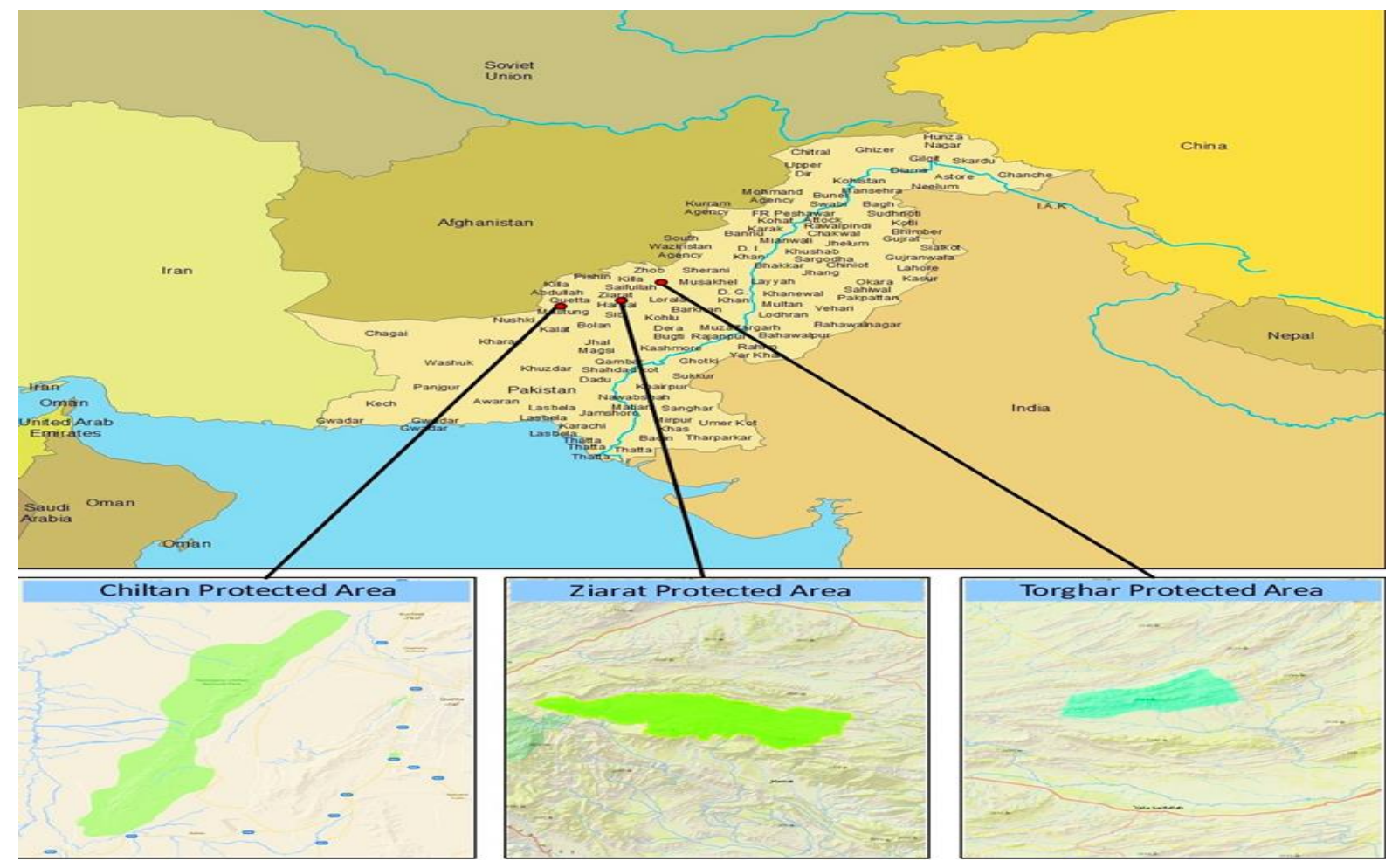

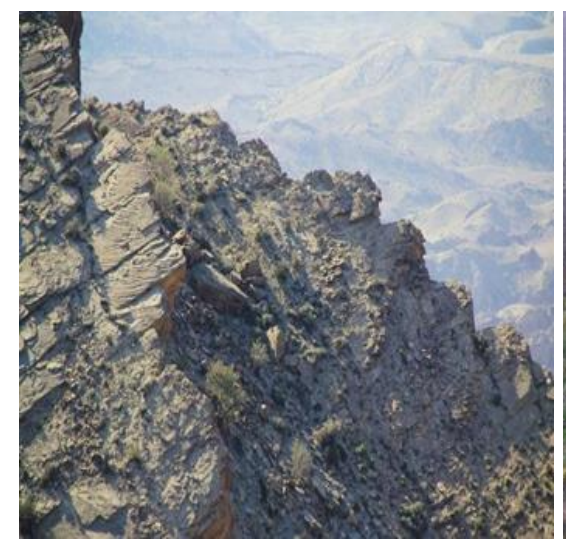

Torghar PA

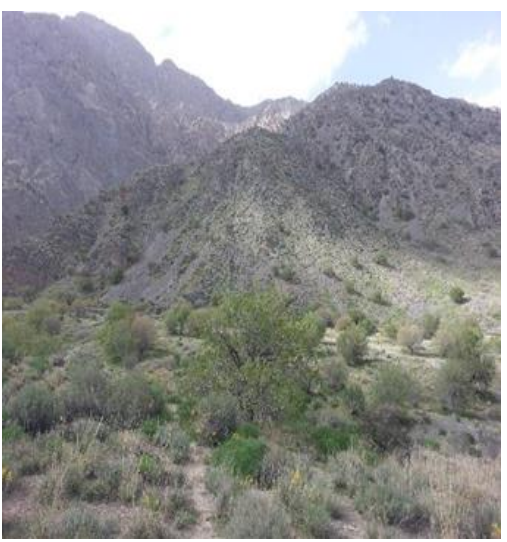

Chiltan PA

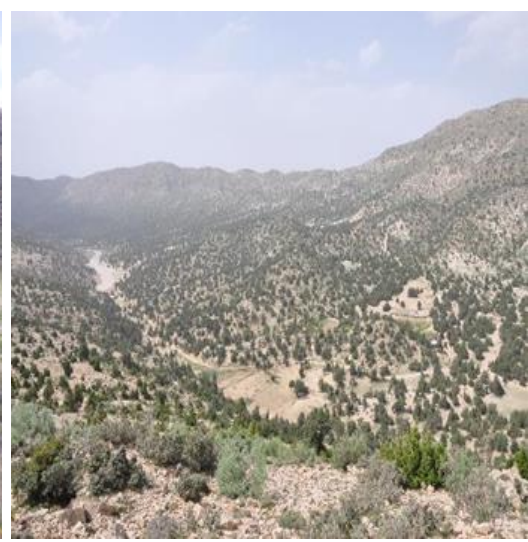

Ziarat PA

Figure 1. Targeted PAs for present in Balochistan, Pakistan

\section{Data analysis}

Score of each questionnaire was entered in the excel spreadsheet and data was analyzed using statistical software SPSS version 20.
The averages and percentages of the categories of planning, process, inputs and outputs/outcomes were calculated for comparative analysis of PAs. 


\section{Results and discussion}

Comparison of overall results with WWF threshold standards

Comparison of overall results of indicators of all three PAs with [11] threshold data showed remarkably diverse results (Figure 2). Most of the indicators were found better than the overall result of [11] report which is very encouraging. The indicators such as PA design, regulations, maintenance of equipment, staff number, laws enforcement, land and water usage planning, security of budget and involvement of local communities scored higher levels and significant differences were observed with the data of world PAs which indicates better management of PAs in Balochistan in our study. In addition, the indicators such as legal status, PA boundary demarcation, PA objectives, management of budget, condition of values and economic benefits slightly crossed the levels of [11] threshold data and indicated better effectiveness of PAs in Balochistan. However, indicators such as research, staff training, education and awareness programs and commercial tourism were found very weak in our study as compared to the [11] threshold data. The causes of weak indicators could be poor governance, security situation in the province and lack of the capacity of line departments and stakeholders. The causes were also highlighted in general discussion with local communities during data collection process. Overall, the management effectiveness of all three PAs (Chiltan National Park, Ziarat Juniper MAB and Torghar) was not only satisfactory but also as like management of PAs at global level.

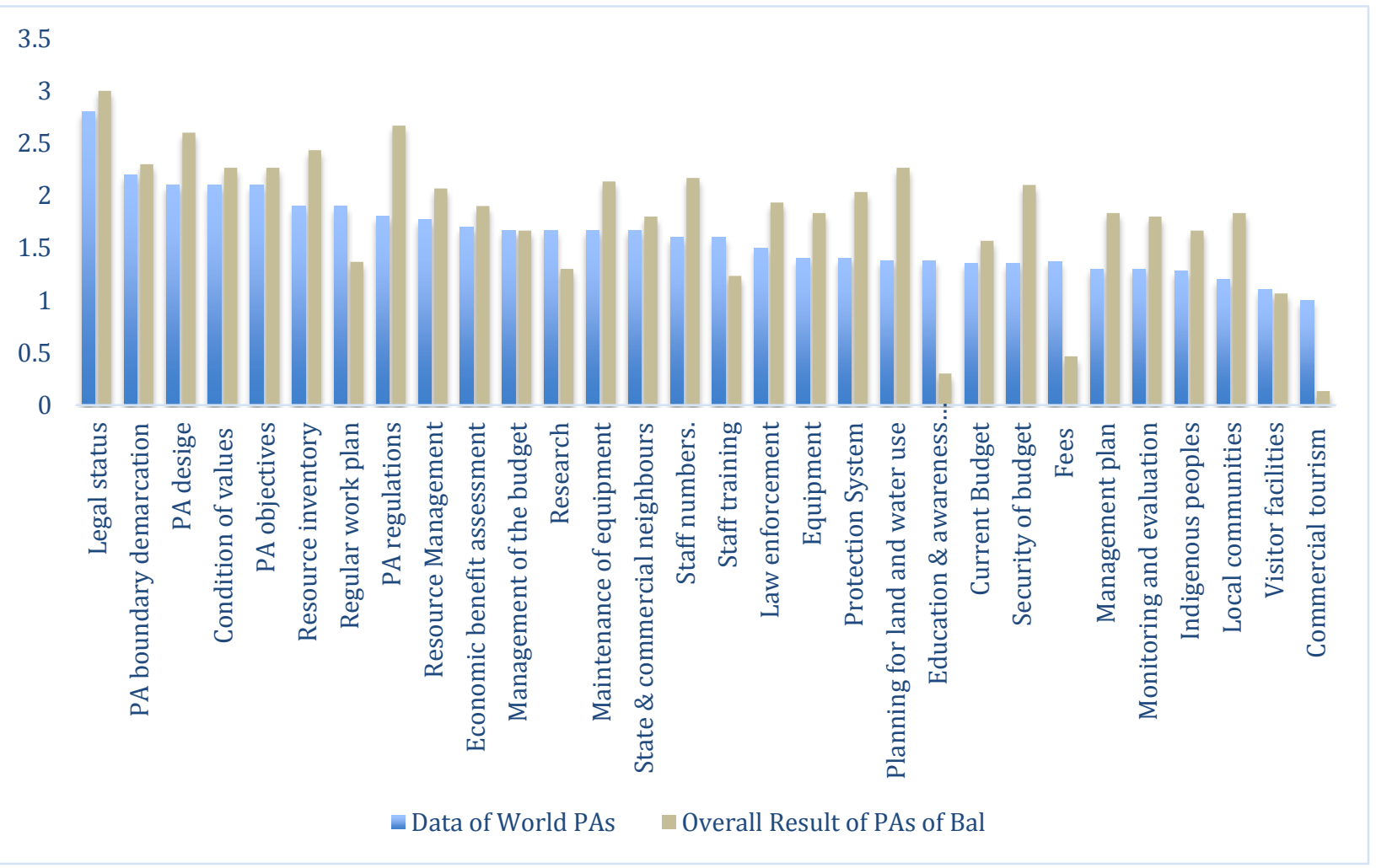

Figure 2. Comparison of overall results with WWF threshold standards 
Comparison of Chiltan National Park results with WWF threshold standards Comparative analysis of Chiltan National Park results with [11] threshold standards revealed two third (20 out of 30 ) of the indicators of Chiltan National Park were on higher levels while one third of the indicators were equal or lower than the indicators of [11] threshold data (Figure 3). The high scored indicators of Chiltan National Park such as boundary demarcation, legal status, regulations, law enforcement are key indicators to demonstrate an effective management whereas the low scored indicators such as research, commercial tourism, fee policy education and awareness programs depend on overall governance and security situation of province rather than effective management and are beyond the scope of effective PA management.

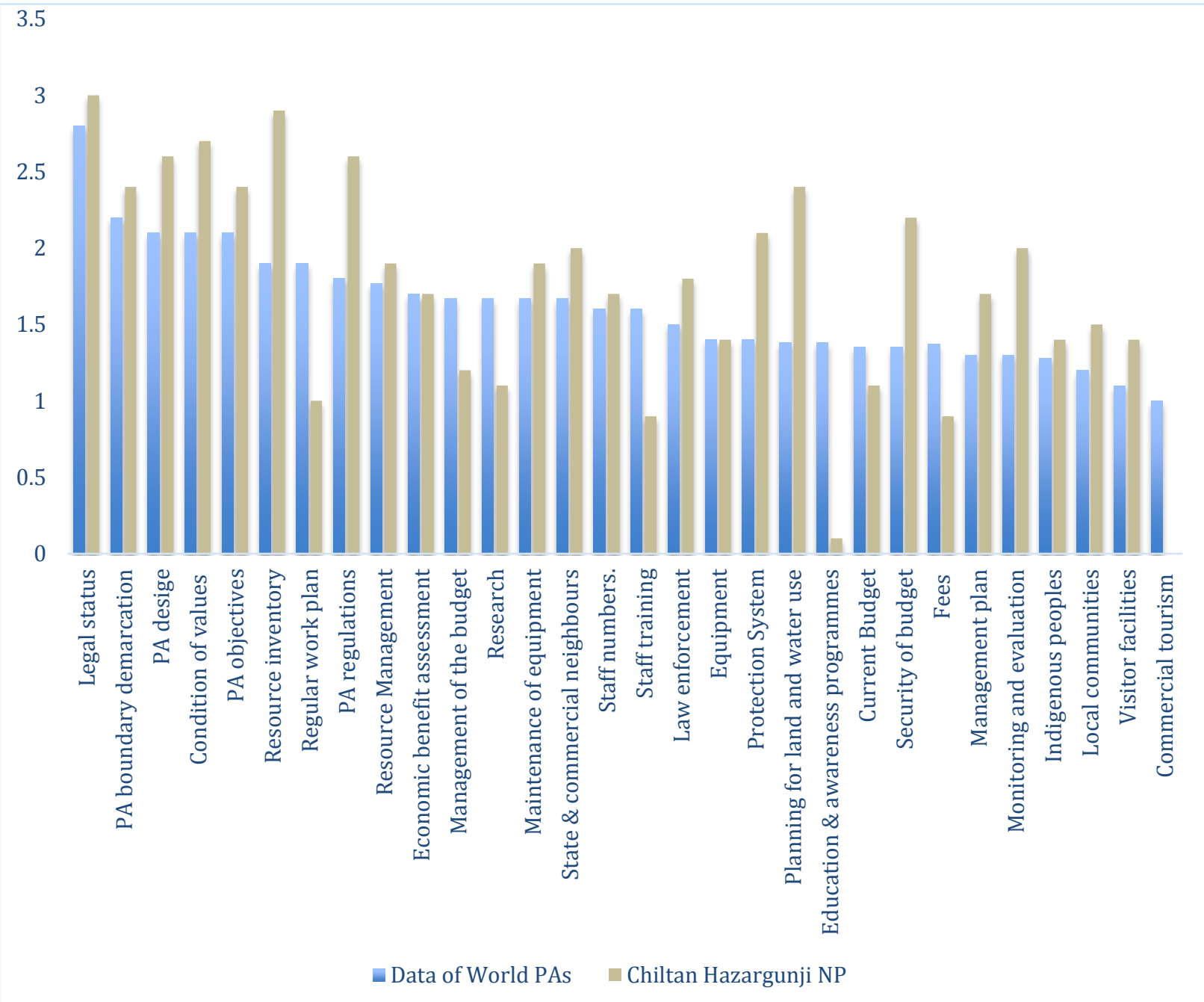

Figure 3. Comparison of Chiltan National Park results with WWF threshold standards

Comparison of Ziarat Juniper MAB with WWF threshold standards

Results of Ziarat Juniper MABin comparison with [11] standards threshold revealed overall the same management standards as of the world PAs (Figure 4) recommended by [11]. Ten indicators i.e. legal context, PA design, PA regulations, management of 
resources, number of staff, laws enforcement, management plan, land and water use, security of budget and involvement of local communities were high scored indicators while the indicators such as regular workplan, condition of values, PA objectives, management of budget, research work, training of staff, education programs and commercial tourism scored were low scored indicators. The other indicators were equal or slightly close to the indicators of threshold standards. The result also revealed the management of Ziarat Juniper MAB was average. The Reason for average management is its recent recognition.

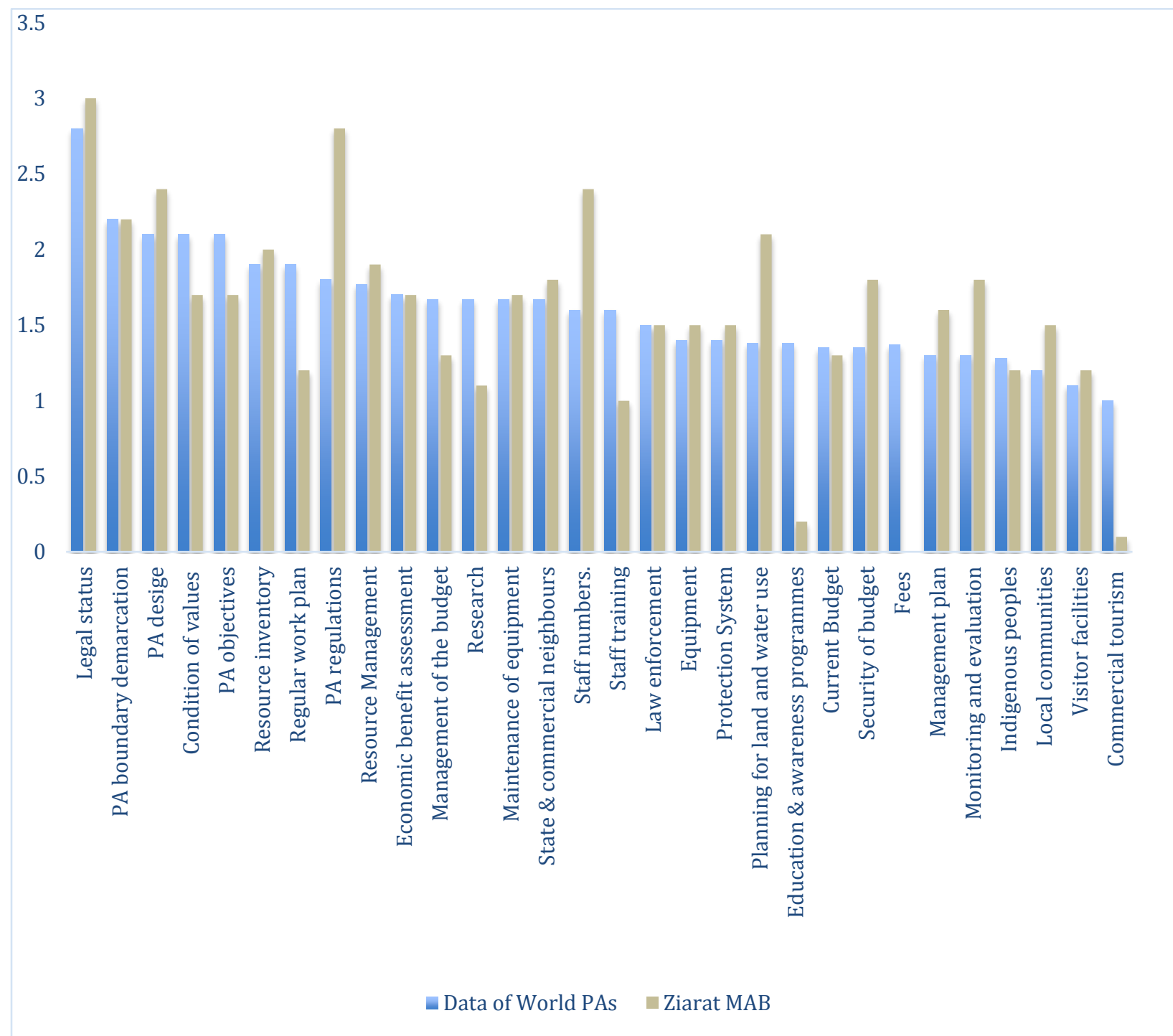

Figure 4. Comparison of Ziarat Juniper MAB with WWF threshold standards

\section{Comparison of TorgharPA with WWF} threshold standards

Torghar is one of community based PAs in Balochistan. The purpose for selection of community based PA was based on hypothesis that if sustainable and effective management is possible with involvement of local communities. Figure 5 showing 
significant result of comparative analysis of Torghar with [11] threshold standards. The results entirely supported our hypothesis. 24 out of 30 indicators were high scored. One indicator i.e. regular work plan was equivalent to threshold standard whereas five indicators (state and commercial neighbours, educational and awareness programs, fee for visitors, facilitation of visitors and commercial tourism) scored less than the indicators of threshold. Consequently, the analysis indicated that the management of Torghar was more effective than the other two PAs. The reasons include no involvement of Government but complete involvement of local communities in PA protection, use of tribal set-up for management, provision of economic benefit in the form of Trophy Hunting to all stakeholders and commitment of local conversions. The causes of the weak indicators are the security situation of the country, remote location, and less accessibility to the area in form of roads and communication.

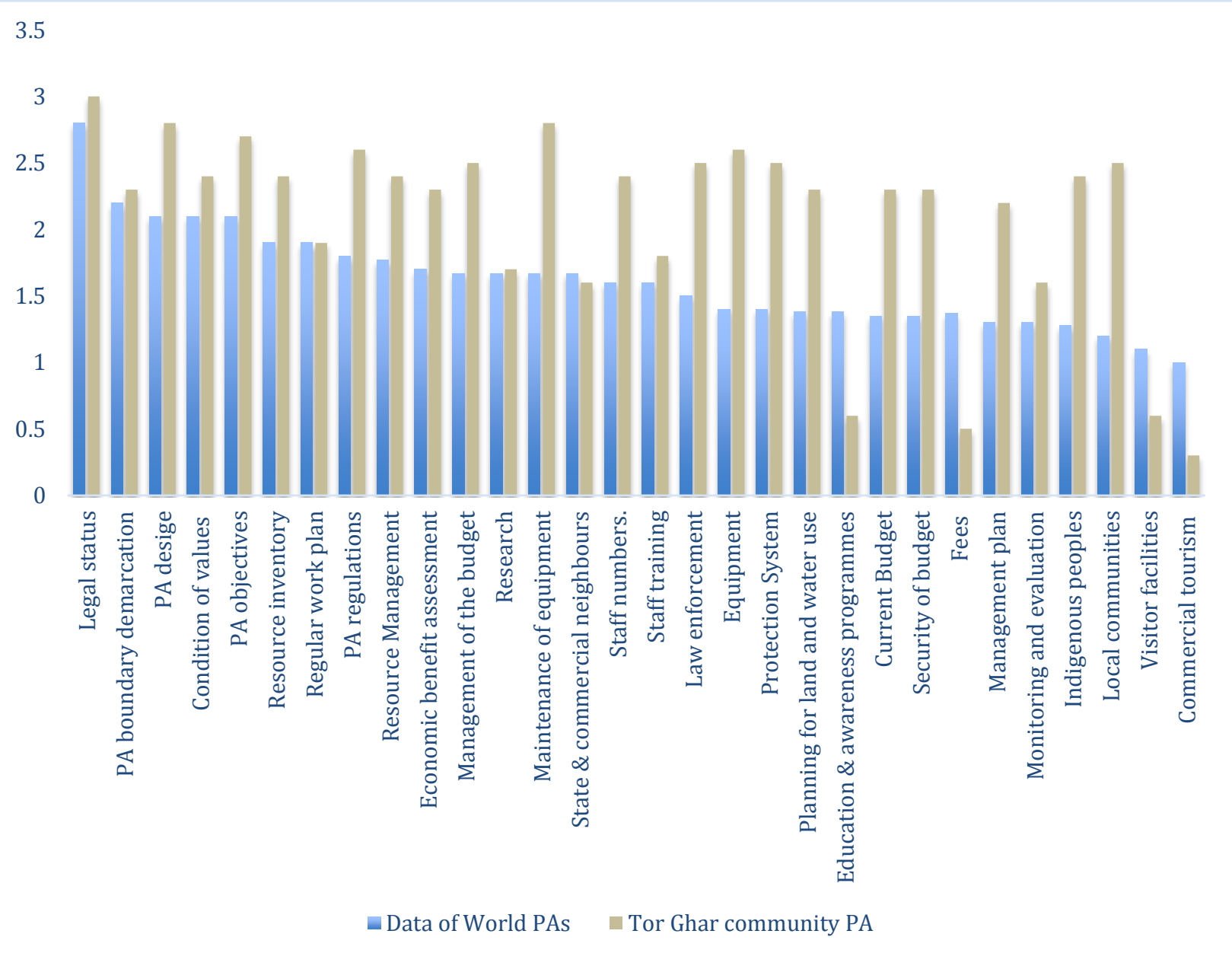

Figure 5. Comparison of Torghar PA with WWF threshold standards

Category wise comparison of PAs with World data

Figure 6 shows category wise comparative analysis of PAs of Balochistan with [11] indicator threshold standards. It was observed that input of Ziarat Juniper MAB less than threshold standards. Outcome of Chiltan National Park was far better than all 
PAs even where Torghar community based PA planning inputs were on lower level. Reasons for better outcome of Chiltan National Park are location of PA near the provincial headquarter of Balochistan where authorities are able to ensure the effective management. The reason for low planning input and outcome of Ziarat Juniper MAB is its recent recognition.

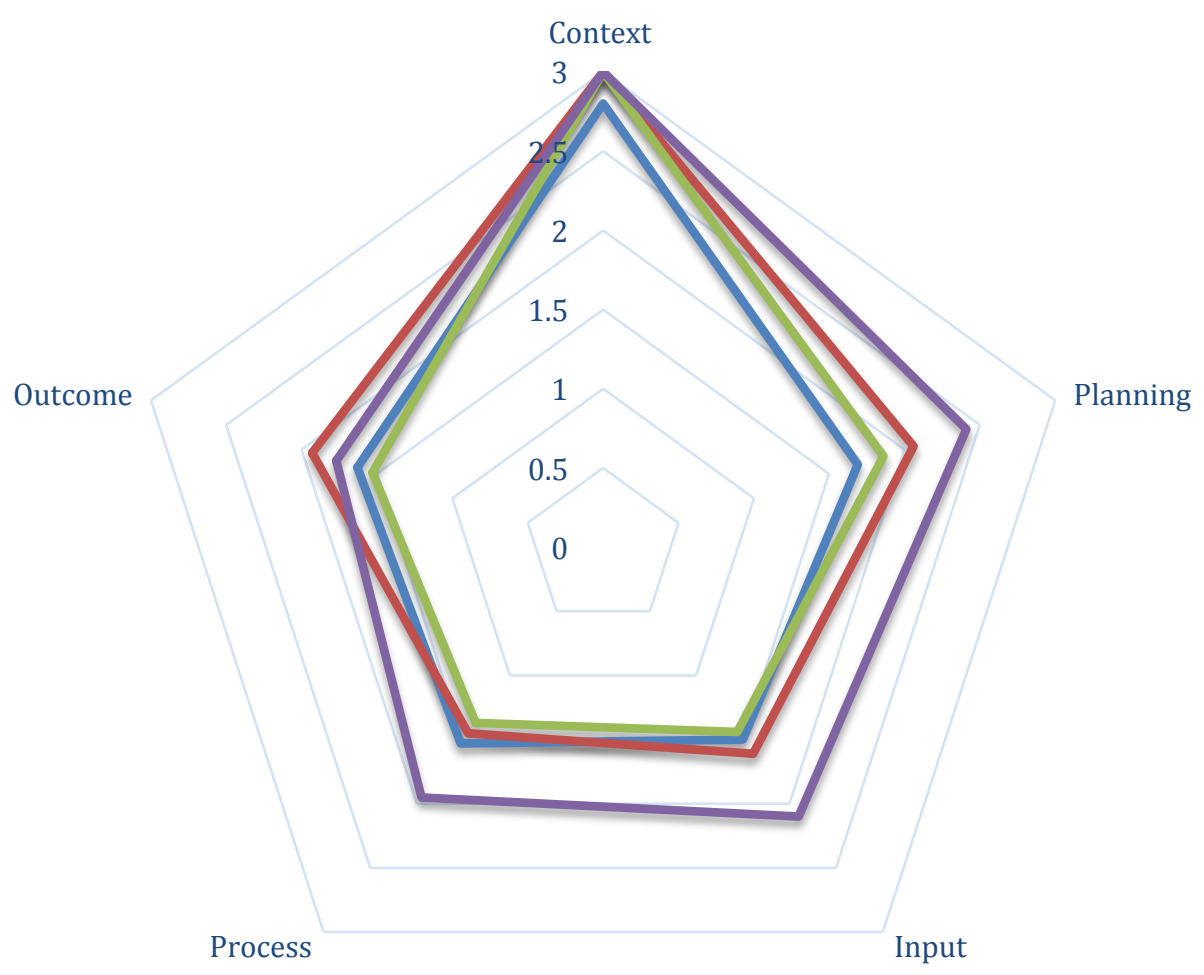

Threshold Data $\rightleftharpoons$ Chiltan $\rightleftharpoons$ Ziarat $\rightleftharpoons$ Torghar

Figure 6. Showing category wise comparative analysis of PAs of Balochistan with WWF (2007) indicator threshold standards

PA management index comparison with test value
In table 1 described major and subcomponents comprising PA management index comparison with test value. 
Kakar et al.

\section{Table 1. Indexed value of major and sub-components comprising of management effectiveness in PAs of Balochistan}

\begin{tabular}{|c|c|c|c|c|c|c|c|}
\hline $\begin{array}{c}\text { Major } \\
\text { Components } \\
\end{array}$ & \multicolumn{3}{|c|}{$\begin{array}{l}\text { Indexed Value of each } \\
\text { Component } \\
\end{array}$} & \multirow[t]{2}{*}{ Sub-Components or indicator } & \multicolumn{3}{|c|}{$\begin{array}{l}\text { Indexed value for each sub- } \\
\text { component (indicator) }\end{array}$} \\
\hline & Chiltan & Ziarat & Torghar & & $\begin{array}{c}\text { IV } \\
\text { Chiltan }\end{array}$ & $\begin{array}{c}\text { IV } \\
\text { Ziarat }\end{array}$ & $\begin{array}{c}\text { IV } \\
\text { Torghar }\end{array}$ \\
\hline Context & 3 & 3 & 3 & $\begin{array}{l}\text { Does the PA has legal position (or covered } \\
\text { by a similar treaty)? }\end{array}$ & 3 & 3 & 3 \\
\hline \multirow{7}{*}{ Planning } & \multirow{7}{*}{2.06} & \multirow{7}{*}{1.86} & \multirow{7}{*}{2.41} & $\begin{array}{l}\text { Are guidelines in place to regulate hunting } \\
\text { and land use? }\end{array}$ & $2.6 * * *$ & $2.8 * * *$ & $2.6 * * *$ \\
\hline & & & & $\begin{array}{c}\text { Is management accepted pertaining agreed } \\
\text { objectives? }\end{array}$ & $2.4 * * *$ & 1.7 & $2.7 * * *$ \\
\hline & & & & $\begin{array}{l}\text { Does PA has ecosystem, waterway of key } \\
\text { conservation concern and habitats for } \\
\text { species protection? }\end{array}$ & $2.6 * * *$ & $2.4 * * *$ & $2.8 * * *$ \\
\hline & & & & $\begin{array}{l}\text { Is there any management plan for } \\
\text { implementation? }\end{array}$ & 1.7 & 1.6 & $2.2 * * *$ \\
\hline & & & & $\begin{array}{c}\text { Is there a regular work plan and is it being } \\
\text { implemented? }\end{array}$ & 1 & 1.2 & 1.9 \\
\hline & & & & $\begin{array}{l}\text { Is PA area recognized to help in } \\
\text { achievement of objectives for land and water } \\
\text { use planning }\end{array}$ & 2.1 & 1.5 & $2.5 * * *$ \\
\hline & & & & $\begin{array}{c}\text { Are PA management activities regularly } \\
\text { monitored? }\end{array}$ & 2 & 1.8 & 1.6 \\
\hline \multirow{8}{*}{ Input } & \multirow{8}{*}{1.61} & \multirow{8}{*}{1.44} & \multirow{8}{*}{2.10} & Can PA staff enforce the rules sufficiently? & 1.8 & 1.5 & $2.5 * * *$ \\
\hline & & & & $\begin{array}{c}\text { Do staff have sufficient knowledge of PA } \\
\text { management? }\end{array}$ & $2.9 * * *$ & 2 & $2.4 * * *$ \\
\hline & & & & $\begin{array}{l}\text { Is there sufficient staff employed for PA } \\
\text { management? }\end{array}$ & 1.7 & 2.4 & $2.4 * * *$ \\
\hline & & & & $\begin{array}{l}\text { Is staff trained enough to meet the objectives } \\
\text { of management? }\end{array}$ & 0.9 & 1 & 1.8 \\
\hline & & & & $\begin{array}{l}\text { Is there sufficient budget for PA } \\
\text { management? }\end{array}$ & 1.1 & 1.3 & $2.3^{* * *}$ \\
\hline & & & & Is budget secure? & $2.2 * * *$ & 1.8 & $2.3 * * *$ \\
\hline & & & & $\begin{array}{l}\text { Is there adequate supply of equipment for } \\
\text { PA management? }\end{array}$ & 1.4 & 1.5 & $2.6 * * *$ \\
\hline & & & & $\begin{array}{l}\text { Is entry or fine fee charged? If yes, does it } \\
\text { help in PA management? }\end{array}$ & 0.9 & 0 & 0.5 \\
\hline \multirow{7}{*}{ Process } & \multirow{7}{*}{1.45} & \multirow{7}{*}{1.37} & \multirow{7}{*}{1.95} & Is PA boundary defined? & 2.4 & 2.2 & $2.3 * * *$ \\
\hline & & & & Is access use of PA resources in control? & $2.4 * *$ & 2.1 & $2.3 * * *$ \\
\hline & & & & $\begin{array}{l}\text { Are management surveys and research } \\
\text { conducted time to time? }\end{array}$ & 1.1 & 1.1 & 1.7 \\
\hline & & & & $\begin{array}{l}\text { Is active management of resources } \\
\text { undertaken? }\end{array}$ & 1.9 & 1.9 & $2.4 * * *$ \\
\hline & & & & $\begin{array}{l}\text { Is budget sufficiently managed to encounter } \\
\text { serious management needs? }\end{array}$ & 1.2 & 1.3 & $2.5^{* * *}$ \\
\hline & & & & Is maintenance of equipment adequate? & 1.9 & 1.7 & $2.8 * * *$ \\
\hline & & & & $\begin{array}{l}\text { Is there any planned Educational program } \\
\text { related to the management objectives? }\end{array}$ & 0.1 & 0.2 & 0.6 \\
\hline
\end{tabular}




\begin{tabular}{|c|c|c|c|c|c|c|c|}
\hline & & & & $\begin{array}{l}\text { Is there any synchronization of PA with } \\
\text { adjacent land and water usage? }\end{array}$ & 2 & 1.8 & 1.6 \\
\hline & & & & $\begin{array}{l}\text { Do traditional and native people of PA have } \\
\text { inputs in decisions of PA management? }\end{array}$ & 1.4 & 1.2 & $2.4 * * *$ \\
\hline & & & & $\begin{array}{l}\text { Do resident local communities of have } \\
\text { inputs in management decisions? }\end{array}$ & 1.5 & 1.5 & $2.5 * * *$ \\
\hline & & & & $\begin{array}{l}\text { Do commercials and operators contribute in } \\
\text { PA management? }\end{array}$ & 0 & 0.1 & 0.3 \\
\hline \multirow{3}{*}{ Outcome } & \multirow{3}{*}{1.93} & \multirow{3}{*}{1.53} & \multirow{3}{*}{1.77} & $\begin{array}{l}\text { Do local communities gain economic } \\
\text { benefits from PA, e.g. employment, income } \\
\text { or payment for services? }\end{array}$ & 1.7 & 1.7 & $2.3 * * *$ \\
\hline & & & & Are there sufficient facilities for visitors? & 1.4 & 1.2 & 0.6 \\
\hline & & & & $\begin{array}{c}\text { What improvements have been observed } \\
\text { after the implementation of important } \\
\text { values? }\end{array}$ & $2.7 * * *$ & 1.7 & $2.4 * * *$ \\
\hline
\end{tabular}

$* * \mathrm{P}<0.05, * * * \mathrm{P}<0.001, \mathrm{~T}$ test for mean difference and significance value

\section{Conclusion}

The present study revealed various significant factors concerning the assessment of management effectiveness of PAs in Balochistan. The very first factor is the overall management of PAs being managed by local communities was more effective as compared to PAs managed exclusively by Government and co-managed by Government and local communities. PA being managed jointly by government and local communities was still better than the PA managed exclusively by Government. The factors observed were good planning and comparatively better utilization resources at PAs being managed by local communities. The second factor observed is Low impact of PA context on their outputs and outcomes was observed and event with the same context of all three PAs was their Registration with WDPA. The outputs and the outcomes are not equal because the planning process and inputs affect management effectiveness of PAs. The third factor is dependence of independent variables that can influence the effectiveness of management of PAs. The fourth factor is control of land use and hunters in PA. Involvement of local communities attaining some economic benefits is more effective.
Local communities play vital role in controlling land, hunting and vegetative cover of PA. In concluded that effectiveness of PAs management depends on the level of involvement of local communities. Involvement of local communities is directly proportional to the effective management of PAs.

\section{Authors' contributions}

Conceived and designed the experiments: S Ainuddin \& FM Kakar, Performed the experiments: FM Kakar, Analyzed the data: FM Kakar, Contributed materials/ analysis/ tools: ZA Bazai \& SUR Kakar, Wrote the paper: FM Kakar.

\section{References}

1. Balmford A, Bruner A, Cooper P, Constanza R, Farber S, Green RE, Jenkins M, Jefferis P, Jessamy $\mathrm{V}$, Madden J, Munro K, Myers N, Naeem S, Paavola J, Rayment M, Rosendo S, Roughgarden J, Trumper K \& Turner RK (2002). Economic Reasons for Conserving Wild Nature. Sci 297(5583): 950-953.

2. Dudley N, Stolton S, Belokurov A, Krueger L, Lopoukhine N, MacKinnon K, Sandwith T \& Sekhran N (2010). Natural Solutions: Protected areas helping people cope with climate change. 
IUCN-WCPA, The Nature Conservancy, UNDP, Wildlife Conservation Society, The World Bank and WWF, Gland, Switzerland and Washington D.C.

3. Dudley, Nigel \& Stolton S (2003). Running Pure: The Importance of Forest Protected Areas to Drinking Water. World Bank, Washington, D.C.

4. Stolton S, Dudley N \& Randall J (2008). Natural Security: Protected areas and hazard mitigation, WWF and Equilibrium, Gland, Switzerland.

5. Mulongoy KJ \& Gidda SB (2008). The Value of Nature: Ecological, Economic, Cultural and Social Benefits of Protected Areas. Secretariat of the CBD, Montreal.

6. Myers N (1996). Environmental Service of Biodiversity. Proc Natl Acad Sci USA 93: 2764-2769.

7. Grujicic I (2009). Assessment of Protected Areas Management

Effectiveness in Serbia: Application of WWF/World Bank Management Effectiveness Tracking Tool in Protected Areas managed by Public Enterprises for Forest Management "SRBIJASUME" and Management of Protected Areas Program, Master Thesis, University of Klagenfurt pp 107.

8. Mehmet S, Ashfaq AK \& Liaqat AW (2009). Review of Protected Areas System in Pakistan: Present Status and Problems Concerning Future Development.

9. Mumtaz K (1989). Pakistan's Environment: A Historical Perspective in Shirkat Gah Women's Resource center, Pakistan's environment: a historical perspective and selected bibliography with annotations Journalists' Resource Center, IUCN Pakistan.

10. Dar GH, Anzar AK, Reddy CS \& Akhtar HM. (2012). Impediment to Taxonomy and Its Impact on Biodiversity Science: An Indian Perspective. Proc Natl Acad Sci India, Sect B Biol Sci 82(2): 235-240.

11. WWF (2007). Tracking progress in managing protected areas around the world. WWF International, Gland, Switzerland. 